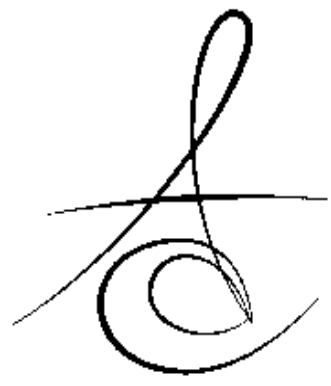

Makale Kodu/Article code: 22195

Makale Gönderilme tarihi: 12.03 .2015

Kabul Tarihi: 16.04.2015

\section{DİJİTAL DENTAL FOTOĞRAFÇILIK-I}

\author{
DIGITAL DENTAL PHOTOGRAPY-I
}

\author{
Prof. Dr. Funda BAYINDIR*
}

\section{ÖZET}

Tarihsel olarak bakıldığında dental fotoğrafların kullanımı ortodonti alanı ile sınırlı kalmıştır. Restoratif diş hekimliğinde de dental fotoğrafların alınmasına ihtiyaç vardır ve dijital dental fotoğraflar estetik dental prosedürlerin gelişmesinde oldukça önemlidir. Ayrıca, estetik uygulamalar için oldukça gerekli ve etkili bir araçtır. Günümüz diş hekimliğinde dental fotoğrafların kullanımı oldukça yaygınlaşmaktadır. Dental fotoğraflar vakaların; bilimsel dergi ve kitaplarda yayınlanmasında, arşivlenmesinde, renk seçimi ve görüntünün laboratuvar ortamına aktarılmasında, hasta ile hekim arasında tedavi seçeneklerinin karar verilmesinde, adli tıpta kimlik tespitinde ve malpraktis davalarında hukuki delil olarak kullanılmaktadır. Bu makalede dijital dental fotoğrafların önemi vurgulanmış ve ağız içi fotoğrafların standardizasyonu açısından genel fotoğrafçılık prensipleri, kameralar, yardımcı ekipmanlar ele alınmıştır.

Anahtar Kelimeler: Dental fotoğrafçılık, DSLR , dijital fotoğraf makinesi, makro çekim

\section{ABSTRACT}

The use of photography in dentistry has historically been limited to the field of orthodontics. There is also a need dental photography for restorative dentistry and digital dental photography has been crucial to the advancement of esthetics dental procedures. In addition, it is an effective and necessary tool for the aesthetic application. Recently in dental practice, the use of dental photography is very common. Dental photography can be used for publishing cases in journal or book, documentation shade matching process and sending data to the dental laboratory, communicating with patient for treatment options, identification for forensic science and the use of legal evidence for malpractice case. This article emphasizes on the significance of digital photography in dentistry and addresses guidelines for general photography, types of camera and the accessories for intraoral photography to make standardized.

Key words: Dental photography, DSLR, digital camera, close-up

\section{GİRIş}

Günümüz diş hekimliğinde vakaların; yayınlanmasında, arşivlenmesinde, renk seçiminde; bilgi ve görüntünün laboratuvar ortamına aktarılmasında dental fotoğraflar oldukça sık kullanmaktadır. ${ }^{1-30}$ Dental fotoğraflar pek çok amaç için alınmaktadır. Hasta hakları çerçevesinde diş hekimi aleyhine açılmış malpraktis davalarının ve şikâyetlerin sayısı gün geçtikçe artmaktadır. Dental fotoğraflar, sadece tedavi aşamalarının kaydedilmesi anlamında değil, aynı zamanda hasta hekim arasında ortaya çıkabilecek anlaşmazlıklarda da çok önemli hukuki delillerdir. ${ }^{17,24}$ Belirli standartlara sadık kalınarak çekilmiş dental fotoğraflar, usulüne uygun olarak da arşivlenerek saklanmalıdır. $2,8,13,21$

Estetik amaçlı yapılan tedavilerin önceki ve sonraki fotoğrafları benzeri tedavi isteği olan hastalarda beklentilerin sınırların çizilebilmesi yönünden büyük fayda sağlar. ${ }^{2,9}$

\footnotetext{
* Atatürk Üniversitesi Diş Hekimliği Fakültesiprotetik Diş Tedavisi Anabilim Dalı
} 
Diş hekiminin tedavi seçenekleri ve hasta beklentileri fotoğraf üzerinde tartışılabilir. ${ }^{14}$

Photo-shop gibi fotoğraf düzenleme programları ile hastanın fotoğrafları üzerinde yapılan düzenlemelerle tedavi sonrası olası sonuçlar hastayla tartışılabilir. $^{2}$

Elektronik ortamda olgu paylaşımlarında en önemli anlatım araçlarından biri görsellerdir. Seminerler, sempozyumlar ve kongrelerde yapılan sunumlar tamamen dijital ortamda hazırlanmaktadır. Dergilerde, kitaplarda yayınlanan makale ve olguların neredeyse tamamında dental fotoğraflar yer almaktadır. ${ }^{2}$

Uygun çekim standartları ile fotoğraflanan ortodontik ve protetik modeller hastanın dosyasında saklanabilir. Böylece yıllar boyu birikerek çok büyük bir hacme intiyaç gösteren arşiv elektronik ortamda saklanmış olur. ${ }^{19}$ Ayrıca adli tıbbı ilgilendiren olgularda dental fotoğraf, kimlik tespitinde röntgenlerle beraber en az parmak izi kadar önemli rol oynar. ${ }^{27}$ Standardize edilmiş çekim prosedürleri uygulanarak elde edilen ve arşivlenen dental fotoğraflar diş hekiminin mesleki yaşamının en önemli tamamlayıcısıdır. ${ }^{23}$ Bir başka deyişle mesleki yaşamının belgeselidir., ${ }^{917} \mathrm{Bu}$ makalede, ülkemizde eğitim veren diş hekimliği fakülteleri çekirdek müfredat programlarında yer almamasına rağmen, meslek hayatımız boyunca sürekli olarak kullandığımız fotoğrafların çekimi sırasında kullanılan ekipmanlar ve temel fotoğrafçılık bilgileri ele alınmıştır.

FOTOĞRAF MAKİNESİ, ANA ELEMANLARI VE GENEL DİjİTAL FOTOĞRAF KAVRAMLARI DSLR FOTOĞRAF MAKİNESİ 5,6,10,15,18,26,29,30

Fotoğraf makineleri birçok kategoriye ayrılsa da temelde objektifi değiştirilebilenler ve değiştirilemeyenler olarak sınıflandırılır. Objektifi değiştirilebilir ürünler arasında ise en çok bilineni Dijital SLR adı verilen modellerdir.

SLR Single Lens Reflex yani 'Tek Objektif Yansımalı' anlamına gelen bir kısaltmadır. DSLR olarak da bilinen Dijital SLR ürünlerin en önemli farkı objektiflerinin değiştirilebilir olması ve kullanıcıya farklı objektiflerle farklı sonuçlar alma imkanı sağlamaktadır.

\section{DIJITAL FOTOĞRAFI OLUŞTURAN} GÖRÜNTÜ SENSÖRLERİ (CCD-CMOS)

Dijital fotoğraf makinelerinde ışı̆̆ın kayıt ortamı foto sensörlerdir. Yani geleneksel (Analog) makinelerde kullanılan filmin görevini üstlenmektedir. Bu sensörler ışığı elektrik yüküne çevirirler . Foto sensörlerin ebatları $35 \mathrm{~mm}$ film yani $24 \times 36 \mathrm{~mm}$ boyutunda ise $\mathrm{FX}$ sensor, $15,8 \times 23,6 \mathrm{~mm}$ boyutunda ise DX sensor olarak tanımlanır. Bu foto sensörlerini oluşturan her bir noktacı̆a piksel (Picture element) adı verilir. Bu pikseller filmdeki grene benzetilebilir. Ancak kimyasal değil elektronik olarak görüntüyü oluştururlar. Pikseller genel olarak kare şeklindedir. Her piksel üzerine düşen ışığın parlaklığına göre bir elektrik yükü oluşturur Bunun için piksellerin sayısı arttıkça iş bölümü de artar ve sonuçta milyonlarca pikselin ürettiği görüntünün kalitesi ortaya çıkar. 12 Milyon Piksel bulunan bir makine için 12 Mega piksel (12MP) tanımı da yapılabilir. Piksellerin oluşturduğu görüntü renkli değildir. Bunun için her pikselin önüne bir filtre gelecek şekilde ızgara şeklinde renk filtreleri bulunur. Bunlara RGB filtre sistemi denir. RGB-filtreleri ana renkler olan Kırmızı (Red)-Yeşil (Green)-Mavi (Blue) süzgeçleri aracılığı ile her pikselin üzerinde bulunan rengi yüklenmesini sağlar . Böylece görüntünün rengi de kaydedilmiş, olur.

\section{Dünyada kullanılan iki tane foto sensör sistemi vardır: CCD ve CMOS \\ CCD (Charged Coupled Device): Yük} Birleştirme Aygıtı anlamına gelen görüntü sensörü sistemidir. Pikseller bu sistemde ışığa maruz kaldıklarında ayrı bir elektrik amplifikatörüne aktarıır ve veri dijitale çevrilir. Bilgilerin bu aktarılma süresi kısa da olsa gecikmeye neden olur. Bu da saniyede kaç fotoğraf çekileceğini belirler.

CMOS (Complymentary Metal Okside Semiconductor): Üstün metal oksit yarı iletken anlamına gelen bir görüntü sensörü sistemidir. CMOS sisteminde her pikselde ışığı dijitale çeviren bir devre bulunmaktadır.

\section{DİYAFRAM/f $\mathbf{5 , 1 1 , 2 6 , 2 9}$}

Diyafram, objektifin içinde gözbebeği gibi açılan ve kısılan bir mekanizmadır. İnsan gözü az ışıklı bir ortamda açıır, çok ışıkı bir ortamda da kısılır. Diyafram da ortamdaki ışığa göre kısılır ve açılır. Böylece makinenin içine girecek ışığın miktarını kontrol eder. Normal gün ışığı için normal diyafram f:8 kabul edilir. Sayısal olarak bunun altındaki değere açık diyafram, üstündeki değere kısık diyafram denir. En açık diyafram f:1,4, en kısık diyafram f:22 dir. Başka bir deyişle f:22 de içeri en az ışık, f:1,4 de en çok ışık girer.

Diyaframın bir başka fonksiyonu da netlikle alakalıdır. Kısık diyaframlarda netlik her zaman fazladır. Açık diyaframlarda ise netlik genelde yayılmaz, bölgesel olur. Alan derinliği, üzerinde odaklama

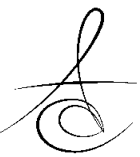


yapılan objenin, kişinin ya da fotoğraflanan konunun önünde ve arkasında oluşan netlik sahasıdır. İngilizce Depth-of-field (DOF) karşılığında kullanılır ve "Net Alan Derinliği" olarak da ifade edilir. Alan derinliği, fotoğrafçının kontrol edebildiği konulardan birisidir. Alan derinliğini kontrol edebilmek için üç farklı unsur bulunmaktadır. Bunların başında diyafram açıklığı gelmektedir. Ayrıca odak uzaklığını ve fotoğraf makinesinin konuya olan uzaklığını kontrol ederek alan derinliği üzerinde kontrol sağlanabilir. Alan derinliğinin büyüklüğü diyafram açıkığı ile ters orantılıdır. Diyaframı ne kadar çok açarsak DOF dediğimiz alan derinliği o kadar çok etkilenir. Yani f/1.8 veya f/2.8 gibi düşük diyafram değerlerinde alan derinliği az olur. Diyaframı ne kadar kısarsak yani f/16 veya f/22 gibi diyafram değerleri kullanırsak alan derinliği o kadar büyük olur. Bazen yetersiz ışık şartlarından dolayı her zaman diyafram ile alan derinliğini kontrol etmek mümkün olmayabilir.

\section{ENSTANTENE/S $\mathbf{5 , 1 1 , 2 6 , 2 9}$}

Enstantane kelime manası olarak zaman aralığı demektir. Sensöre düşecek ışığın süresini kontrol eder. Obtüratör, perde hızı da aynı anlamdadır. Perde ve aynanın yukarı aşağı hareketinin hızıdır. Perde fazla süreyle açık kalırsa içeriye girecek ışık miktarı artar. Daha az süre açık kalırsa da ışık miktarı azalır. Enstantane değerleri: 1/1- 1/2- 1/4-1/8 -1/151/30 - 1/60 - 1/125-1/250-1/500-1/1000sn

Örneğin:1/250 enstantane saniyenin 250 de biri manasına gelir. $1 / 1$ enstantane de 1 sn dir. $1 / 1000$ ise çok kısa bir süredir. Gün ışığı için normal enstantane değeri 125 enstantanedir. Bunun sayısal olarak altına düşük enstantane, üstüne de yüksek enstantane hızı denir. Yani 1/15 düşük enstantane 1/1000 yüksek enstantanedir. Buradan yola çıkarak ışığın az olduğu bir mekanda içeri daha fazla süre ışık girmesi için düşük enstantane, ışık çok ise az süre ışık girmesi için yüksek enstantane kullanılmalıdır. Enstantane ayrıca hareketli objelerin görüntülenmesinde dikkate alınması gereken bir faktördür. Yüksek enstantaneler hareketi dondurur. hareketli konuları duruyormuş, gibi fotoğraflama mızı sağlar. Düşük enstantaneler ise fotoğrafa hareket hissi katar.

\section{ASA (ISO) ${ }^{5,11}$}

Görüntü sensörünün ışık hassasiyetidir . Yüksek ASA larda ışık hassasiyeti artar. Düşük ışık koşullarında ASA arttırılarak pozlamanın dengeli olması sağlanabilir . Çekim yaptığımız ortamda ışık az ise düşük enstantene değeri kullanıır ya da flaş kullanılarak yüksek enstantene değerine çıkılır Ortamın kendi ışığı kaybedilmemek isteniyorsa flaşsız örneğin $\quad 1 / 20$ gibi düşük bir enstantene ve f :2,8 gibi açık bir diyaframla ile çekim yapılır. Ancak bu hızda tripotsuz elde çekim yapılırken makinenin titreme olasılığı yüksektir . Aynı zamanda açık diyafram değerlerinde netlik daha azdır . Bu aşamada yapılması gereken ASA yı yükselterek , yüksek bir enstantene ve daha kısık bir diyaframa ulaşmaktır.

$5,11,12,26$

WB (WHITE BALANCE) BEYAZ AYARI

Işığın rengi ışık kaynağının rengine göre deği şiklik gösterir .İnsan gözü ışık kaynağının rengindeki değişikliklere adapte olabilir ve sonuçta ister gölgede , ister doğrudan güneş, ışı̆̆ında isterse parlak ışık altında olsun beyaz objeleri beyaz görür. Filmli kameralarda kullanılan filmin aksine dijital kameralar resimleri ışık kaynağının rengine göre işleyerek bu ayarlamanın bir benzerini yapabilmektedir. Bu işlem "beyaz ayarı" olarak bilinir. Işığın rengi ısısıyla ilgilidir . Işığın ıSıSı KELVİN (K) ile gösterilir. Kelvin-metre ile ölçülür . Ana ışık kaynağı olan güneşin ， gün doğumunda renk sıcaklığı 3100-4300 Kelvin, gün ortasında 5000-7000 Kelvin, kapalı-bulutlu bir havada 6000-8000 Kelvin ve günbatımında 2500-3100 Kelvin arasında değişir. Kelvin dereceleri 5500 K'nin altına doğru indiğinde renk spektrumunun sıcak tonlarına doğru gideriz yani sarı , yeşil , turuncu ve kırmızı renkler fotoğrafa hakim olmaya başlar. $5500 \mathrm{~K}$ üstüne çıkıldığında ise soğuk tonlara yani mavi renge doğru gidilir.

\section{YARDIMCI EKİPMANLAR ${ }^{10}$}

TRİPOD (ÜÇ AYAK): Fotoğrafçının en önemli yardımcı ekipmanı tripoddur. Üç ayak üzerinde yere basan ve makinemizin altına bir vidalama sistemi ile takılan tripodlar amatör kullanıcı için ve profesyonel kullanım için değişik ebatlarda ve çeşitli malzemelerle üretilmektedir. Tripod un en önemli fonksiyonu düşük ışık koşullarında düşük enstantane kullandığımız durumlarda (1/15) elimizdeki titremeleri önlemektir. $\mathrm{Bu}$ sayede makinemizi tipoda bağlayarak 30sn bile pozlamada bile net bir fotoğraf elde edebiliriz. Bunun için ayrıca kablo deklanşör, ya da uzaktan kumanda gibi tetikleyiciler kullanarak, makinemize el sürmeden uzun pozlamalar yapılabilir.

Tripodların kullanım amaçlarından bir diğeri de fotoğrafın keskinliği arttırmaktır . Gün ışığı ya da yeterince aydınlatılmış, alanlarda bile netliği arttırmak için kısık diyafram kullanmak gerekir. Çünkü kısık

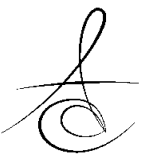


diyaframlarda net alan derinliği artar. Bu durumda pozlamayı dengelemek için düşük enstantane kullanmak gerekir. Makinemizi böyle bir durumda tripoda bağlayıp en kısık diyaframa (f:22) getiririz. Enstantane de o oranda aşağı çekilir. (1/20) Bu sayede fotoğrafın netliği ve keskinliği artar. $^{10}$

MAKRO (CLOSE-UP) OBJEKTİFLER $\mathbf{5 , 8 , 2 6 , 2 9}$

Dental fotoğraf çekimlerinde kullanılan bu objektifler, 50 mm, 100 mm, 200 mm gibi değişmez açılı objektiflerdir. Nikon için 55, 105 ve 200 mm olarak üretilmiştir. Konuya $1 / 1$ ile $1 / 10$ gibi oranlarda çok yakın çekimlerde, özellikle de dental ve doğa fotoğrafçılığında kullanılır. Dental fotoğraf çekimleri için en ideal Makro lensler; 60 mm,85 mm,90 mm,100 $\mathrm{mm}, 105 \mathrm{~mm}$ 'dir.

\section{FLAŞLAR $5,12,26,29$}

Fotoğraflarımızın kalitesini arttıracak önemli bir ekipmandır. Kompakt ya da DSLR Makinelerin hepsinin üstünde kendi dahili flaşları bulunur. Ancak bu flaşlar cephe aydınlatması yaparak sadece konuyu standart biçimde aydınlatır. Cephe aydınlatmasında detaylar azalır ve gölgeler yok denecek kadar azalır. Ayrıca fotoğrafın derinlik hissi kaybolur. ${ }^{28} \mathrm{Bu}$ fotoğrafta çok istenmeyen bir neticedir. Bu noktada devreye makinenin üstündeki flaş kızağına bağlanan harici flaşlar (Nikon SB-800 SB-600) girer. Bu harici flaşlar Nikon D SLR makinelerin TTL ölçüm sistemine göre tasarlanmıştır. Flaşı makinenize taktığınızda makine flaşı tanır ve flaş patladıktan sonra objektife girecek ışığı algılar . Bunun için makinelerin P konumunda da doğru neticeler elde edilir . Bu Flaşların en önemli fonksiyon larından biri de flaş kafalarının sağa sola ve yukarı döndürülerek Bounce Hareketi denilen hareketi sağlamalıdır. Bounce hareketi sayesinde cephe aydınlatmasından kurtulurak yandan ve üsten aydınlatma sağlanır. Ayrıca ikili ya da üçlü flaş kombinasyonu ve renkli jelleri kullanarak daha profesyonel neticelere ulaşılabilir. Kullanım bakımından dental makro çekimler için tasarlanmış (R1C1) özel flaşlar ve ring flaşlar bulunmaktadır. (Resim. 1 ve 2)

\section{FÍLTRELER ${ }^{31}$}

Objektifin önüne takılan genellikle silindir şeklinde camdan yapılmış bu filtrelerin ışık ve renk dengeleme, koruyucu ve efekt filtreleri olarak farklı işlevleri vardır. Her objektifin çapının aynı olmaması nedeni ile her objektif için farklı çaplarda filtreler bulunur. Filtrelerden en çok kullanılanlar:

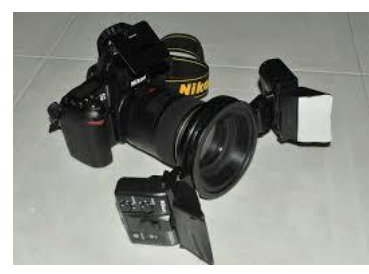

Resim I. Harici R1C1 flaşı

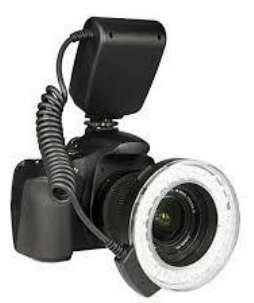

Resim 2. Dental fotoğraflar için ring flaş
UV ve Skylight Filtreler: Ultra-viyole ışınlarını süzme görevi yapan UV filtreler ， renksiz yapıları sayesinde olumsuz bir etkileri yoktur . Eğer ortamda insan gözünün göremediği ama fotoğrafı etkileyecek UV ışınları var ise bu filtre bu ışınları süzerek fotoğraf yüzeyinde sisli bir tabaka oluşmasını engellerler . Bu filtreler aynı zamanda objektifi toz , çizilme, yağlanma gibi dış etkilerden korur . Benzer şekilde sky light filtrelerde aynı görevi görürler. Ancak sahip oldukları hafif pembe renk nedeni ile renklerde kontrast arttırıcı özelliği vardır.

Polarize Filtreler: Polarize filtreler üç önemli amaç için kullanıırlar . Birincisi yansımaları önlemesi , ikincisi renklerin doygunluğunu arttırması üçüncüsü ise yoğunluk filtresi gibi iş görmesidir. Polarize filtre, ışığın objektife giriş açısını kontrol ederek metal olmayan yüzeylerden kaynaklanan yansımaları önler . Dairesel bir hareket ile kontrol edilen filtre , her yönden gelen ışığı geçirmez, yalnızca belirli bir açı ile karşıdan gelen ışığı geçirir.

Yoğunluk (ND) Filtreleri: Çok kısık bir diyafram değeri ve çok düşük bir enstantane kullanmamız gerektiğinde ve bu değerler makinamızda yok ise gri yoğunluk filtresi en önemli yardımcımızdır . Gri renkteki bu filtreler filme gelen ışığı iki veya dört stop hatta sekiz stop azaltırken renklerde değişikliğe neden olmazlar.

Yumuşatıcı Filtreleri: Yumuşatıcı (soft) veya diffüzer (yayıcı) filtreler daha çok portre çekimleri için idealdir. Bu filtreler, özellikle portre fotoğraflarında yüz hatlarını ve çizgilerini yumuşatmaları ve aydınlık bölgelere gölge vermeleri nedeni ile kullanılırlar.

Isıtıcı (Warm-up) Filtreler: Bu filtreler fotoğrafa yumuşak bir turuncu ton vererek sıcaklık sağlarlar. $81 \mathrm{~A}, 81 \mathrm{~B}$ ve $81 \mathrm{C}$ gibi farklı ısıtıc filtreler vardır. Burada $A$ en zayıf ,C en kuvvetli filtreyi temsil etmektedir. 81A filtre portre çekimlerinde ten rengine bir canlılık katmaktadır. Burada unutulmaması gereken filtrelerin sadece ortamda var olan ton veya renkleri kuvvetlen-

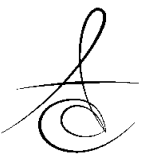


dirmiş, ol duğudur yani ortamda olmayan renk ve tonları yoktan var edemezler. (Resim 3)

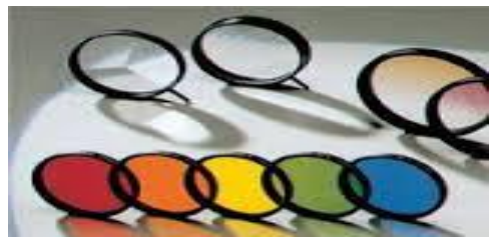

Resim 3. Farklı amaçlar için kullanılan fitreler

\section{AYNALAR $5,10,29,30$}

İntraoral fotoğraf çekimlerinde yetişkin ve çocuk hastalar için farklı boyutlarda tasarlanmış özel metal veya sırlanmış cam aynalardır. Özellikle oklüzal ve bukkal yüz çekimlerinde kullanılırlar. Metal aynalar yüksek teknoloji ile parlatılmış paslanmaz çelikten üretilirler, kırılma riski olmadığı için klinik kullanım için oldukça avantajlıdır. (Resim 4)

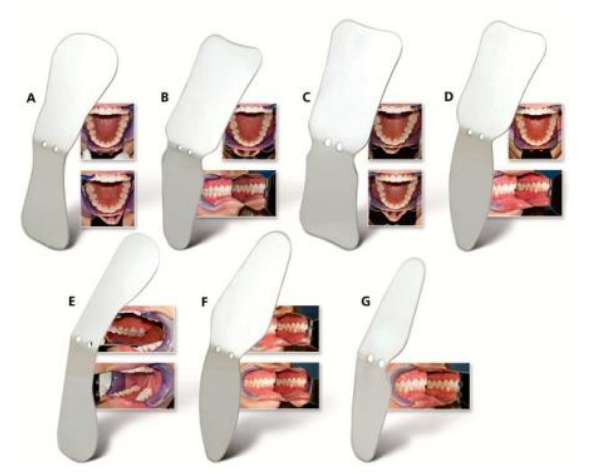

Resim 4. Ağız içi fotoğraflar için oklüzal ve bukkal yüz çekimleri için özel olarak tasarlanmış aynalar

\section{EKARTÖRLER ${ }^{5,10,26,29,30}$}

İntra oral fotoğrafların alınmasında dudak ve yanağı ekarte etmek amacıyla kullanılırlar, metal veya plastikten üretilirler. Dental fotoğraflarda ışık yansımasına sebep olmaması ve farklı renk algılanmamasına sebep olmaması açısından şeffaf plastik ekartörlerin kullanılması önerilmektedir. (Resim 5)

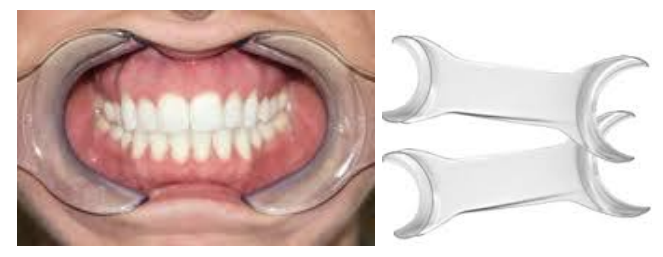

Resim 5. Ekartörler

\section{KONTRAST PLAKLAR ${ }^{5,10,26}$}

Özellikle ön grup dişlerde alınan görüntülerde arkada siyah bir fon elde etmek için kullanılır. Özellikle anterior dişlerin insizal translüsensliği ve mamellonların yansıtılması ve arkın dışında kalan bölgelerin maskelenmesi amacıyla kullanılmaktadır. (Resim 6)

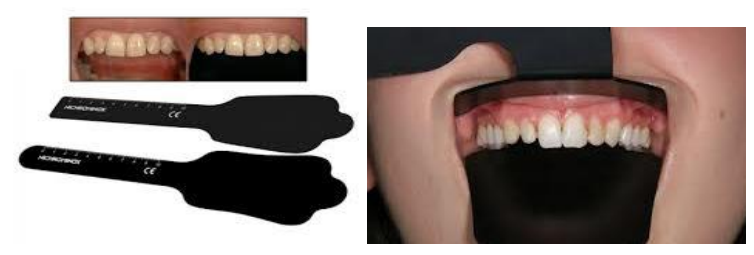

Resim 6. Kontrast Plaklar

\section{HAFIZA KARTI ve YEDEK PİL ${ }^{30,31}$}

Hafıza kartları, dijital fotoğraf makinesinin filmleri gibidir. bir elektronik bellektir ve makinenin içerisine takılır. çok az enerji tüketirler defalarca yazılıp silinebildikleri için, limitsiz çekim olanağı temin ederler. günümüzde Compact Flash (CF) en yaygın olanıdır ama Memory Stick (MS), Smart Media gibi türleri vardır. Özellikle klinik çalışmalar sırasında kritik anlarda pilin bitmesi ve hafıza kartını dolması riskine karşı mutlaka yedek olarak bulundurulmalıdır. (Resim 7)
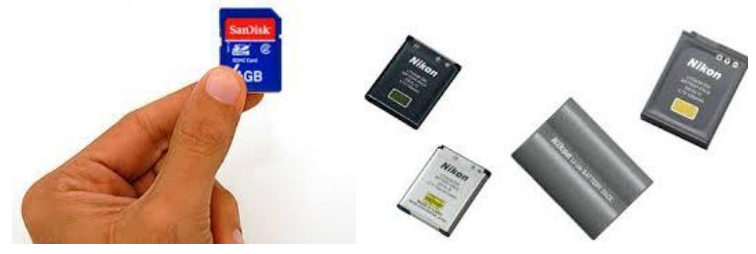

Resim 7. Hafıza kartı ve yedek pil

\section{UZAKTAN KUMANDA DEKLANŞÖR ${ }^{31}$}

Fotoğraf çekimi sırasında özellikle yüksek enstantane değerlerinde deklanşöre basış anında titremelerin önlenmesi amacıyla uzaktan kumandalı deklanşörler kullanılır. Kablolu veya kablosuz olarak üretilmişlerdir. (Resim 8)
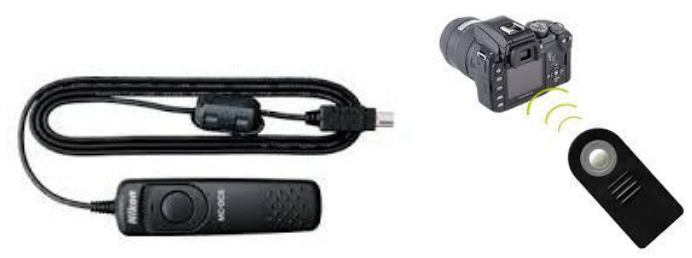

Resim 8. Uzaktan kumanda deklanşör 


\section{ÇEKİM MODLARI ${ }^{31}$}

$P$ (Program): Program modunda makine ortamdaki ışığa göre enstantene ve diyafram değerlerini otomatik olarak verir.

S/TV (Enstantane önceliği): Bu konumda makineye enstantane değeri manuel verilir. Buna karşlık gelecek diyafram değerini makine otomatik olarak verir.

A/AV (Diyafram önceliği) Bu konumda makineye diyafram değeri manuel verilir. Buna karşlık gelen enstantane değeri makineye bırakılır.

M (Manuel Pozlama): Enstantane ve diyafram fotoğrafçı tarafından manuel olarak verilir. Kamera ayarları mutlaka her çekim öncesi incelenmeli ve doğru olduğu kontrol edilmelidir. ${ }^{5}$ (Resim 9)

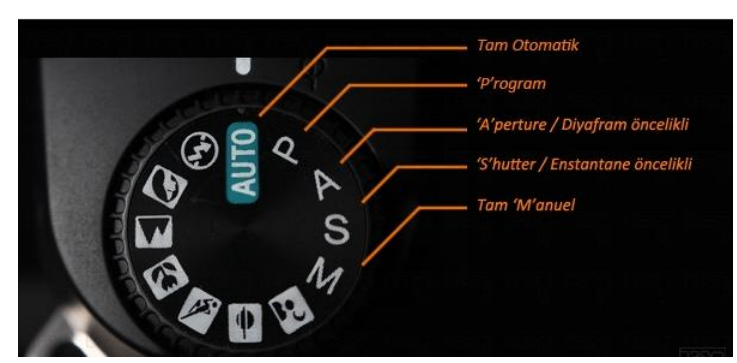

Resim 9. Çekim modları

\section{DİJİTAL FOTOĞRAF MAKİNELERİNDE KAYIT FORMATLARI ${ }^{5,6,10,11,23}$}

Dijital fotoğraf makinelerinde 3 kayit formatı bulunur: JPEG,TIFF ve RAW

JPEG: Sık sık karşılaştığımız, The Joint Photographic Experts Group (JPEG) formatı, gerçek renk değerlerini içeren bir sıkıştırma formatıdır. Görüntünün algılanması için çok gerekli olmayan detayları bulup atarak dosyayı sıkıştırdığından kayıplı formatlar arasında anilır. Kaybedilen detayların geri getirilmesi mümkün olmadığından, dosyanın kopyasını kayıpsız bir yöntem ile korumakta yarar vardır. Görüntü kalitesi, göz tarafında orijinalin aynısı gibi görünse de, yine de kayıplar mevcut olacaktır.

TIFF: TIFF formatı yani Tagged-Image File Format, farklı işletim sistemleri ve uygulamalar arasında kayıpsız ve esnek bir dosya değiş, tokuşu sağla ması nedeniyle tüm çalışmalar için uygun bir format olarak bilinir. TIFF formatı, RGB, CMYK, LAB gibi neredeyse tüm renk birimlerini destekler. TIFF'in desteklediği pek çok sıkışııma programı olmasına rağmen en çok kullanılanı LZW sıkıştırma yöntemidir. TIFF ayrıca çok sayıda alfa kanalı desteklemektedir. Dijital fotoğrafın medyaya (Compact Flash, Smart Card vs.) kaydedilirken kullanılan, tercihe bağlı olarak değişik tipte sıkışırma seçeneklerine imkan sağlayan ancak her şart altında JPEG'den daha fazla yer kaplayan bir resim formatıdır.

RAW: Dijital Fotoğrafların "Negatifi" olarakta bilinir. Nikon Fotoğraf Makinelerinde özel RAW formatının adı NEF'dir (Nikon Elektronik Format). RAW farklı bilgisayar ve işletim sistemleri arasında bilgi iletimine izin veren esnek bir formattır. Kanal sayısı, her kanaldaki piksel derinliği, dosya uzantısı ve başlık bilgileri tanımlanabilir. Her türlü renk modunda kayıt yapma imkanı sunar. RAW formatı, çekilen fotoğraflara özel programlarla beyaz ayarı'da dahil olmak üzere pek çok ayara müdahale etmeye imkan verir.

\section{SONUÇ}

Meslek hayatımız boyunca kullandığımız dental fotoğraflar üzerine hazırlanmış çok az sayıda yerli yayın bulunması, lisans eğitimi sırasında çekirdek eğiti$\mathrm{m}$ müfredatında bulunmaması nedeniyle bu alanda $\mathrm{ki}$ bilgi eksikliği özel eğitim programları ile giderilebilir ve başarıı bir vakanın, görüntülenme sırasında oluşan fotoğraf hataları ile gölgelenmesi engellenebilir.

\section{KAYNAKLAR}

1. Dunn JR, Hutson B, Levato CM. Photographic imaging for esthetic restorative dentistry. Compend Contin Educ Dent 1999;20:766-8.

2. Ahmad I. Digital dental photography. Part 2: Purposes and uses. Br Dent J 2009;9;206:459-64.

3. Terry DA, Snow SR, McLaren EA. Contemporary dental photography: selection and application. Compend Contin Educ Dent 2008;29:432-6.

4. Dunn J, Beckler G. Digital photography technology offers unique capabilities, advantages, and challenges to dental practices. J alif Dent Assoc 2001;29:744-50.

5. Engin Ö. Dental Fotoğrafçllık. Quintesence yayıncillk 2011.

6. Shagam J, Kleiman A. Technological updates in dental photography. Dent. Clin. North Am 2011; 55:627-33, 
7. Ahmad I. Digital dental photography. Part 3: Principles of digital photography. Br Dent J 2009; 23;206:517-23.

8. Haak R, Schirra C. Dental photography in support of patient documentation and communication. Quintessence Int 2000;31:649-57.

9. Ahmad I. Digital dental photography. Part 1: an overview Br Dent J 2009;206:403 -7.

10. Ahmad I. Digital dental photography. Part 4: Choosing a camera. Br Dent J. 2009;13;206:57581.

11. Ahmad I. Digital dental photography. Part 6: Camera settings. Br Dent J 2009;25;207:63-9.

12. Ahmad I. Digital dental photography. Part 5: Lighting Br Dent J 2009;11;207:13-8

13. McLaren EA, Schoenbaum T. Digital photography enhances diagnostics, communication, and documentation. Compend Contin Educ Dent 2011; 32:4,36-8.

14. Christensen GJ. Important clinical uses for digital photography. J Am Dent Assoc 2005;136(1):77-9.

15. Bengel W. Digital photography in the dental practice--an overview (II). Int J Comput Dent 2000; 3:121-32.

16. Wee AG, Lindsey DT, Kuo S, Johnston WM. Color accuracy of commercial digital cameras for use in dentistry. Dent Mater 2006; 22:553-9.

17. Morse GA, Haque MS, Sharland MR, Burke FJ. The use of clinical photography by UK general dental practitioners. Br Dent J 2010; 9;208:1-6

18. Dunn J, Beckler G. Digital photography technology offers unique capabilities, advantages, and challenges to dental practices. J Calif Dent Assoc 2001; 29:744-50.

19. Snow SR. Assessing and achieving accuracy in digital dental photography. J Calif Dent Assoc 2009 ;37:185-91.

20. Griffin JD Jr. Excellence in photography: heightening dentist-ceramist communication. Dent Today 2009; 28:124-7.

21 . Ward $\mathrm{DH}$. The vision of digital dental photography. Dent Today 2007; 26: 100,102,104-5.

22. Weston JF, Haupt E. Creating aesthetic success through proper clinician and laboratory technical communication. Dent Clin North Am 2011; 55:37182.
23. Desai V, Bumb D. Digital dental photography: a contemporary revolution. Int J Clin Pediatr Dent 2013; 6:193-6.

24. Wander $P$. Dental photography in record keeping and litigation. Br Dent J 2014; 216:207-8.

25. Sharland MR. An update on digital photography for the general dental practitioner. Dent Update 2008; 35:398-400, 402-4.

26. Lazar D, Cimpian S, Stratul S. An introduction of dental photography. A guide on specific cameras and accessories. TMJ 2011;1-2: 107-11.

27. Bernstein ML. The application of photography in forensic dentistry. Dent Clin North Am 1983; 27:151-70.

28. Ho C. Clinical photography: a picture can tell thousand words. Dent Pract 2004:148-54.

29. McLaren EA, Terry DA. Photography in dentistry. J Calif Dent Assoc 2001; 29:735-42.

30. Manjunath SG, RajuRagavendra T, Sowmya KS, Jayalakshmi K. Photography in clinical dentistry. A Review. Int J Dent Clin 2011; 3: 40-3.

31. Kılavuz E. Temel fotoğraf bilgileri. http://www. erdemkilavuz.com/wp-content/uploads/ temel_fotografcilik.pdf

\section{Yazışma Adresi}

Prof. Dr. Funda BAYINDIR

Atatürk Üniversitesi

Diş Hekimliği Fakültesi

Protetik Diş Tedavisi AD.

ERZURUM

TIf: +90 $4422360944-1751$

Fax: +90 4422360945

E-mail: fundabayindir(Cgmail.com 